\title{
NUMERICAL INVESTIGATION OF GROUND COOLING POTENTIAL FOR MALAYSIAN CLIMATE
}

\author{
T.M. Yusof ${ }^{1,2}$, S. Anuar ${ }^{1}$, and H. Ibrahim ${ }^{1}$ \\ ${ }^{1}$ Faculty of Mechanical Engineering \\ Universiti Malaysia Pahang, 26600 Pekan, Pahang, MALAYSIA. \\ *E-mail: myusof@ump.edu.my \\ Phone: +60 9424 6257; Fax: +60 94246222 \\ ${ }^{2}$ Automotive Engineering Centre \\ Universiti Malaysia Pahang, 26600 Pekan, Pahang, MALAYSIA.
}

\begin{abstract}
In equatorial countries like Malaysia, the cooling of buildings is almost entirely dependent on air-conditioning, with electricity as the main source of the energy required. As the country develops, with more buildings being built, and as the population grows, with more people demanding thermal comfort in the buildings they work and live in, the rate of electricity consumption for cooling purposes will continue to increase dramatically from year to year. This phenomenon requires the application of alternative energy options and thermal storage. Ground thermal storage is an example of thermal storage which can supply cooling and heating effects resulting in a significant reduction of electricity consumption. This paper discusses the potential of the implementation of ground thermal storage by using a ground heat exchanger (GHE) to supply passive cooling for any application. An analysis has been conducted based on an empirical equation from conduction heat transfer for depths of up to $30 \mathrm{~m}$ and thermal diffusivities from 0.04 to $0.1 \mathrm{~m}^{2} / \mathrm{day}$. The main input parameters were obtained from a local weather station for three consecutive years. The result showed that a significant reduction occurs at a depth of $2.0 \mathrm{~m}$ and below, meaning that cooling can be supplied constantly throughout the year. The temperature amplitude is also attenuated relatively with depth, whereby amplitudes of less than $1{ }^{\circ} \mathrm{C}$ occur at a depth of more than $4 \mathrm{~m}$ with a thermal diffusivity of $0.04 \mathrm{~m}^{2} / \mathrm{day}$. In addition, thermal diffusivity gives a significant increment in temperature amplitude and it is suggested to be maintained at a value of less than $0.06 \mathrm{~m}^{2} /$ day. This result provides useful information to researchers and engineers in the field of underground installation of materials or systems such as gas pipelines, water supply and for underground cable transmittance.
\end{abstract}

Keywords: Ground heat exchanger; mathematical model; underground temperature variation.

\section{INTRODUCTION}

Maintaining a comfortable temperature inside a building requires a significant amount of energy, for which heating and cooling systems are often used. The energy required to operate such systems generally comes from electricity, fossil fuels and biomass, which indicates a drastic increment in their consumption from year to year. Generally, global energy consumption in the building sector accounts for more than $35 \%$ of the world's total energy demand, of which $75 \%$ is for space heating and domestic water heating [1- 
4]. However, electricity consumption in Malaysia includes $29 \%$ of final annual electricity consumption for space cooling alone. Heating is not necessary in Malaysia and in similar countries located in the equatorial region such as Singapore, Northern Brazil, Somalia, Kenya, Ecuador and Indonesia.

Malaysia is located between $1^{\circ}$ and $7^{\circ}$ North in latitude and $100^{\circ}$ and $120^{\circ}$ East in longitude. The average daytime temperature is about $31^{\circ} \mathrm{C}$, which is on the high side of the thermal comfort zone. The temperature of $24{ }^{\circ} \mathrm{C}$ is commonly considered a human comfort level in both commercial and residential buildings. The demand for electricity for cooling is ever-increasing and leads to the utilization of renewable energy and sources of thermal storage such as the ground [5]. The ground has a high thermal inertia, where about $46 \%$ of the energy from the sun is absorbed by the earth, which causes temperature fluctuations at the ground surface attenuating deeper into the ground. Therefore, a time lag occurs between the temperature fluctuations at the surface and in the ground. At a sufficient depth, the ground temperature is lower than the air temperature in summer and higher than the air temperature in winter. When ambient air is drawn through a buried pipe called a ground heat exchanger (GHE), the air is cooled in summer and heated in winter [6]. This air can be used for human comfort by means of ventilation and other applications such as for thermal storage, and for cooling or heating of agricultural greenhouses. Investigation of the underground temperature at different depths is necessary to identify the potential of GHE implementation and a suitable depth at which the pipes should be buried. Kusuda and Achenbach [7] and Argiriuou [8] reported that the ground temperature is different for different geographical locations. Florides and Kalogirou [9] reported underground temperature variation at various depths during summer and winter. The temperature is nearly constant below a depth of $5 \mathrm{~m}$ throughout the year. Chow et al. [10] analysed the soil temperature in Hong Kong based on data available from 1995 to 2009. The analysis was conducted at different depths, from the ground surface to a depth of $3 \mathrm{~m}$. Different depths showed different temperatures, and the depth of $3 \mathrm{~m}$ presented small temperature amplitudes compared with other depths. The lowest temperature obtained was $22.5{ }^{\circ} \mathrm{C}$ and the highest was $27.5{ }^{\circ} \mathrm{C}$. Pfafferot [6] and Pfafferot et al. [11] presented average annual temperature profiles at depths of $1 \mathrm{~m}, 2 \mathrm{~m}, 4 \mathrm{~m}$ and $8 \mathrm{~m}$. Their findings showed that the temperatures at depths of 4 and $8 \mathrm{~m}$ are consistent throughout the year, in the range of 9 to $13^{\circ} \mathrm{C}$. Ascione et al. [12] conducted a study of underground temperature as part of a main research in implementing GHE for an air-conditioned building during winter and summer. Their finding is that the configurations for the GHE at a depth of $3 \mathrm{~m}$ for summer and winter show a good compromise between energy performance and the cost of excavation. Krishnan and Rao [13] found a significant heating and cooling potential from various soil locations investigated in India. Sharan and Jadhav [14] measured and simulated a soil temperature regime up to $3 \mathrm{~m}$ depth with $1 \mathrm{~m}$ intervals. The temperature amplitude becomes attenuated with depth, with values of $2.8^{\circ} \mathrm{C}$ at $3 \mathrm{~m}$ depth compared with $4.6{ }^{\circ} \mathrm{C}$ at $1 \mathrm{~m}$ depth. Additionally, results from this work have been applied on GHE for buildings and greenhouses [15, 16]. Al-Ajmi et al. [17] conducted measurements and a simulation study of soil temperature for a hot and arid climate. The temperature is attenuated from $13.3{ }^{\circ} \mathrm{C}$ at the ground surface to $3.95{ }^{\circ} \mathrm{C}$ at a depth of 4 $\mathrm{m}$. Derbel et al. [18] investigated the soil temperature variation at different depths and types of soil using neural network prediction. Four types of soil and four different depths were considered. The results showed that different thermal diffusivities produce different temperature variations, although the same depth was maintained. 
A few studies have been conducted for ground temperature variations in Malaysia. Alam et al. [19] conducted a study on energy efficiency using a geo-cooling system. However, the ground temperature was not investigated in the study. The researchers used ground temperature variations based on China's climate [20]. In China the lowest temperature of $19.7{ }^{\circ} \mathrm{C}$ was obtained at a depth of $10 \mathrm{~m}$ and this value has been implemented in the analysis for Malaysia. Sanusi et al. [21] summarized that a depth of $1 \mathrm{~m}$ could give optimum performance to GHE for Malaysia's climate. Temperature variations obtained were based on only two seasons: the wet and dry seasons. However, several issues still affect the successful implementation of GHE in Malaysia. The issues are: i) determining the underground temperature for yearly variations at different depths, ii) establishing a ground weather station, iii) carrying out a soil properties study related to thermal behaviour, and iv) establishing analytical or numerical equations to determine the underground temperature for the Malaysian climate. Towards GHE implementation, this paper discusses underground temperature variations by considering different depths and thermal diffusivities. The rationale of this analysis is that different depths of ground will result in different temperature variations and thermal diffusivities. Therefore, the optimal depth at which to install the GHE can be identified in order to produce significant cooling. Besides the temperature, this paper also highlights analytical and correlation equations that have been developed according to Malaysian conditions. These equations are used to determine the underground temperature and temperature amplitude for the Malaysian climate.

\section{MATHEMATICAL MODEL}

Mathematical models to study temperature variations under the ground have been developed by a number of researchers since the late 1950s [7, 22-24]. Their findings showed that the ground temperature is dependent on latitude, altitude, weather conditions, time of year, shading, landscaping, soil properties and rainfall. These parameters have significant effects on the heat flow within the earth. Most of these models treat the ground as a semi-infinite and homogeneous heat-conducting medium. The basic equation of heat conduction used in developing the mathematical model of soil temperature variation is shown in Eq. (1):

$$
\frac{\partial^{2} T}{\partial_{z}^{2}}=\frac{1}{\alpha}\left(\frac{\partial T}{\partial t}\right)
$$

The final equation to determine the temperature of the ground at a certain depth and time $\left(T_{z, t}\right)$ can be expressed by Eq. (2):

$$
T_{z, t}=T_{a}-A_{s} \exp \left[-z\left(\frac{\pi}{365 \alpha}\right)^{1 / 2}\right] \cos \left\{\left(\frac{2 \pi}{365}\right)\left[\left(t-t_{0}\right)-\left(\frac{z}{2}\right)\left(\frac{365}{2 \alpha}\right)^{1 / 2}\right]\right\}
$$

where:

$T_{a}=$ Average temperature of the soil surface $\left({ }^{\circ} \mathrm{C}\right)$.

$A_{s}=$ Amplitude of surface temperature variation $\left({ }^{\circ} \mathrm{C}\right)$.

$z=$ Depth of soil $(\mathrm{m})$. 
$\alpha=$ Thermal diffusivity of the ground $\left(\mathrm{m}^{2} / \mathrm{h}\right)$.

$t=$ Time elapsed from the beginning of the calendar year (day).

$t_{o}=$ A phase constant (day) since the beginning of the year of the lowest average ground surface temperature (day).

$T_{m}, A_{s}$ and $t_{o}$ can be determined from the local weather station using a statistical approach. However, the thermal diffusivity should be determined accurately at the location where the study is conducted, and this requires knowledge of the type of soil and moisture content. In most cases, there is no detailed information about the soil characteristics and furthermore the moisture varies throughout the year. However, there is a guideline provided by ASHRAE [25] which considers common types of sand, different water content, density and thermal diffusivity. The thermal diffusivity ranges on average from 0.04 to $0.1 \mathrm{~m}^{2} /$ day. In addition, most researchers have used different values of thermal diffusivity in their work [14, 17, 18, 26-29].

In the present work, the local ambient temperature has been obtained from Weatherspark for three consecutive years from 2010 to 2012. From the data, three important parameters have been determined: i) mean temperature of the soil surface $\left(T_{m}\right)$, ii) amplitude of surface temperature variation $\left(A_{s}\right)$, and iii) phase constant $\left(t_{o}\right)$. The thermal diffusivity is taken in the range of 0.04 to $0.1 \mathrm{~m}^{2} /$ day, which is suggested by ASHRAE and has been used by previous researchers. Comparison of the simulation results with references [14, 17, 18] is also discussed in this paper. These three references are selected because of having a similar average temperature $\left(T_{m}\right)$ to Malaysia's condition.

\section{RESULTS AND DISCUSSION}

\section{Statistical Analysis of Average Temperature}

Statistical analysis of ambient temperature is obtained from Weatherspark for Station 34038, Sultan Haji Ahmad Shah Airport, Kuantan. Figure 1 shows the daily average temperature for the three consecutive years. Hourly temperatures have been obtained and the mean daily temperature was $26.9^{\circ} \mathrm{C}$. The lowest and highest temperatures were $22.7^{\circ} \mathrm{C}$ and $34{ }^{\circ} \mathrm{C}$, respectively. The amplitude of surface temperature is obtained as 5.7 ${ }^{\circ} \mathrm{C}$ and the phase constant $\left(t_{0}\right)$ where the lowest temperature is taken at day 365 on the basis of the daily average temperature (Figure 2). The empirical equation to determine underground temperature variation in Malaysia is shown in Eq. (3).

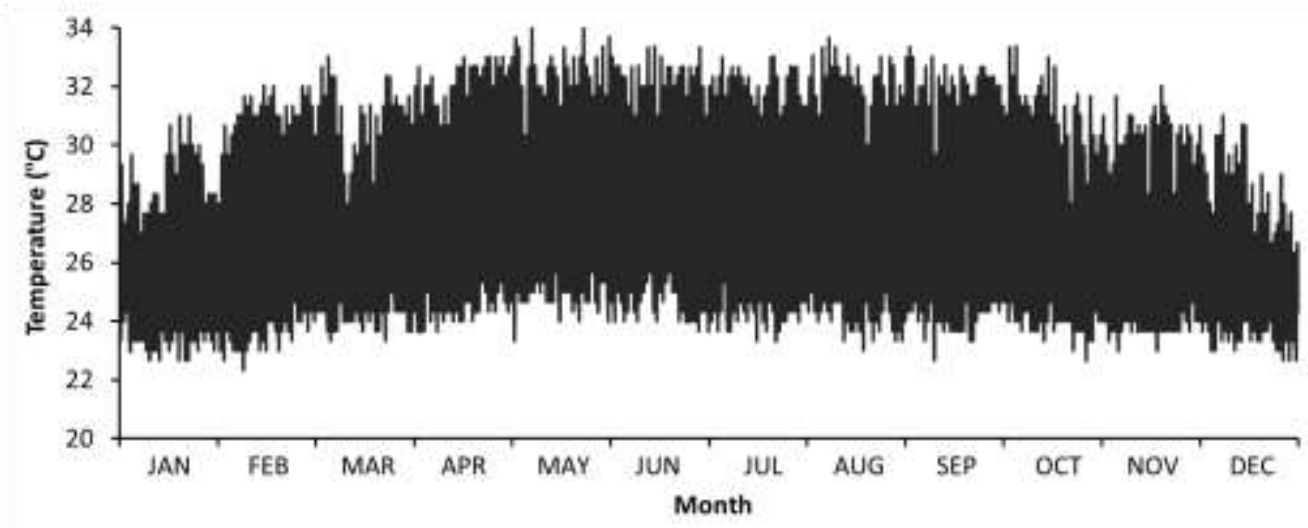

Figure 1. Average three-year (2010-2012) air temperature at Kuantan. 


$$
T_{z, t}=26.9-5.67 \exp [-z a] \cos \left[\frac{2 \pi}{365}(t-365)-z a\right]
$$

where:

$$
a=\left[\frac{\pi}{365 \alpha}\right]^{0.5}
$$

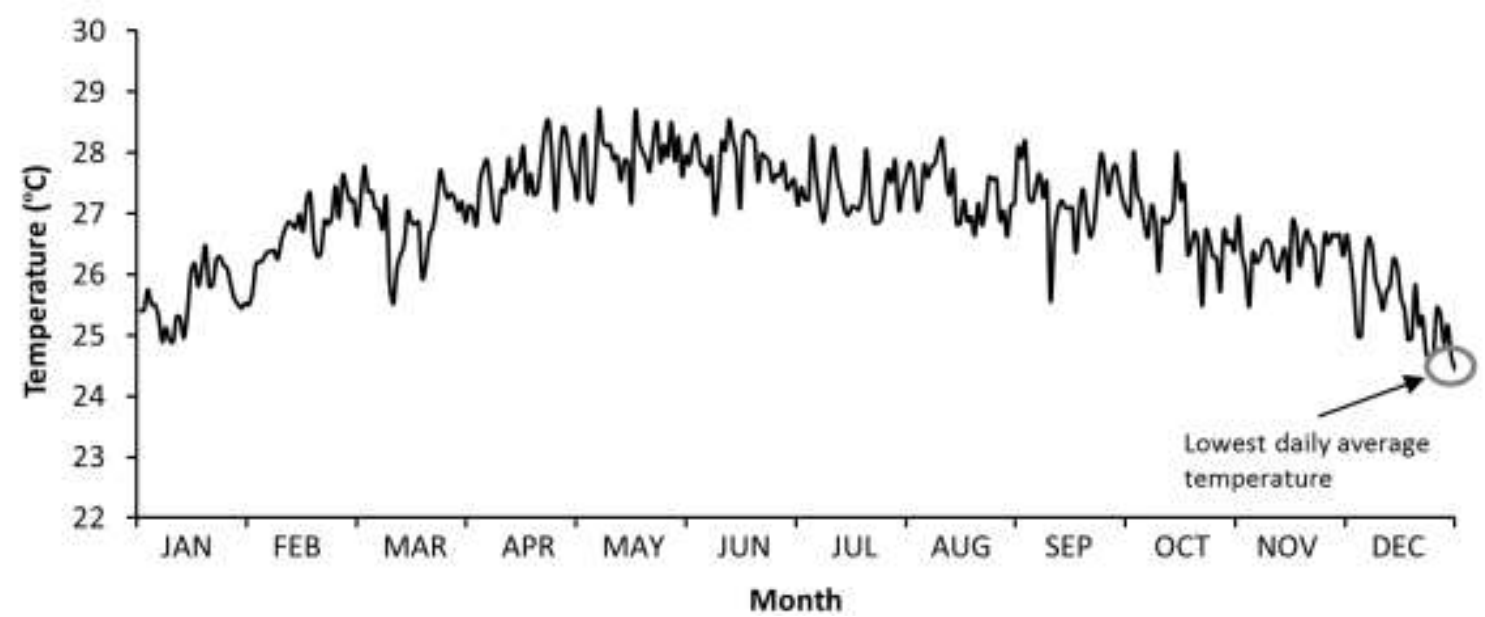

Figure 2. Daily average temperature for three years (2010-2012) at Kuantan.

\section{Ground Temperature}

Analysis of underground temperature variation has been conducted up to $6 \mathrm{~m}$ depth and the thermal diffusivities were taken in the range of 0.04 to $0.10 \mathrm{~m}^{2} /$ day. Eq. (3) is used to determine the underground temperature using MATLAB software. Results from the simulation have been manipulated in the form of graphs, as shown in Figure 3, which is a time-temperature curve at different depths and thermal diffusivities $(0.04,0.06,0.08$ and $0.1 \mathrm{~m}^{2} /$ day). The same sine-wave graphs have been obtained throughout the timetemperature graph. However, their amplitudes are different at the same depth of the ground. This is due to the thermal diffusivity, where higher thermal diffusivity shows heat moving rapidly through the soil. Therefore, higher temperature variation of the ground has been obtained for higher thermal diffusivity. The other finding in this study is that the variation of the amplitude is attenuated relative to the depth of the ground for the range of the thermal diffusivity shown in Figure 4. In the application of GHE, the amplitude of temperature should be kept as small as possible so that the effect of cooling by the ground can be utilized at the optimum condition. In addition, low thermal diffusivity will enable the GHE to remain functional at low temperature output. One possible explanation is that the heat is moving slowly in this region from its source. Therefore, thermal diffusivity at $0.06 \mathrm{~m}^{2} /$ day and below looks more significant and rational in the application of GHE due to the reduction of the amplitude by about half from the range of analysis. Additionally, the variation of ground temperature is slightly lower than the other ground temperature variation for thermal diffusivities above 0.06 $\mathrm{m}^{2} /$ day. 

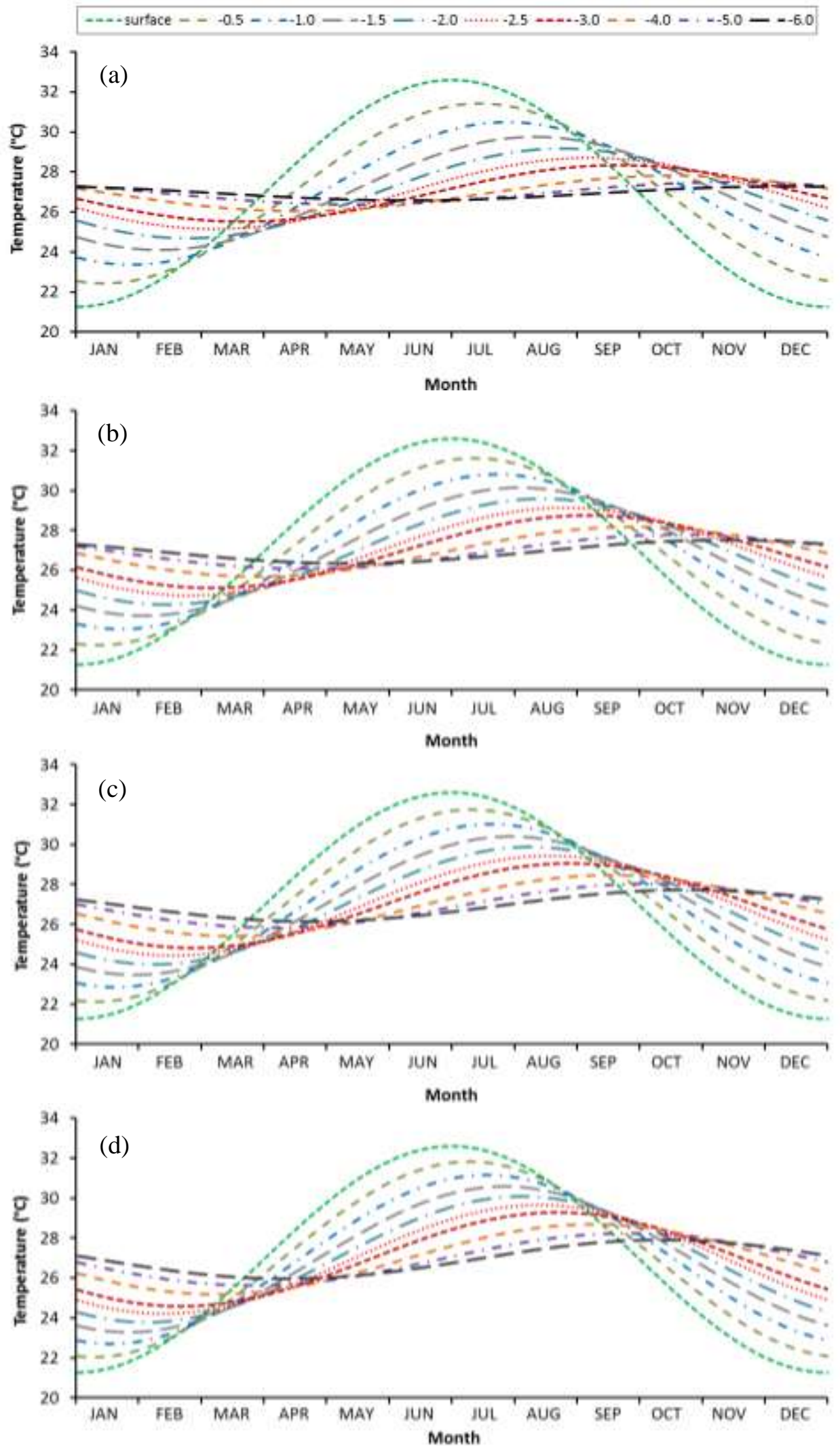

Figure 3. Time-temperature graph for thermal diffusivities of (a) $0.04 \mathrm{~m}^{2} / \mathrm{day}$, (b) 0.06 $\mathrm{m}^{2} /$ day, (c) $0.08 \mathrm{~m}^{2} /$ day, and (d) $0.10 \mathrm{~m}^{2} /$ day. 


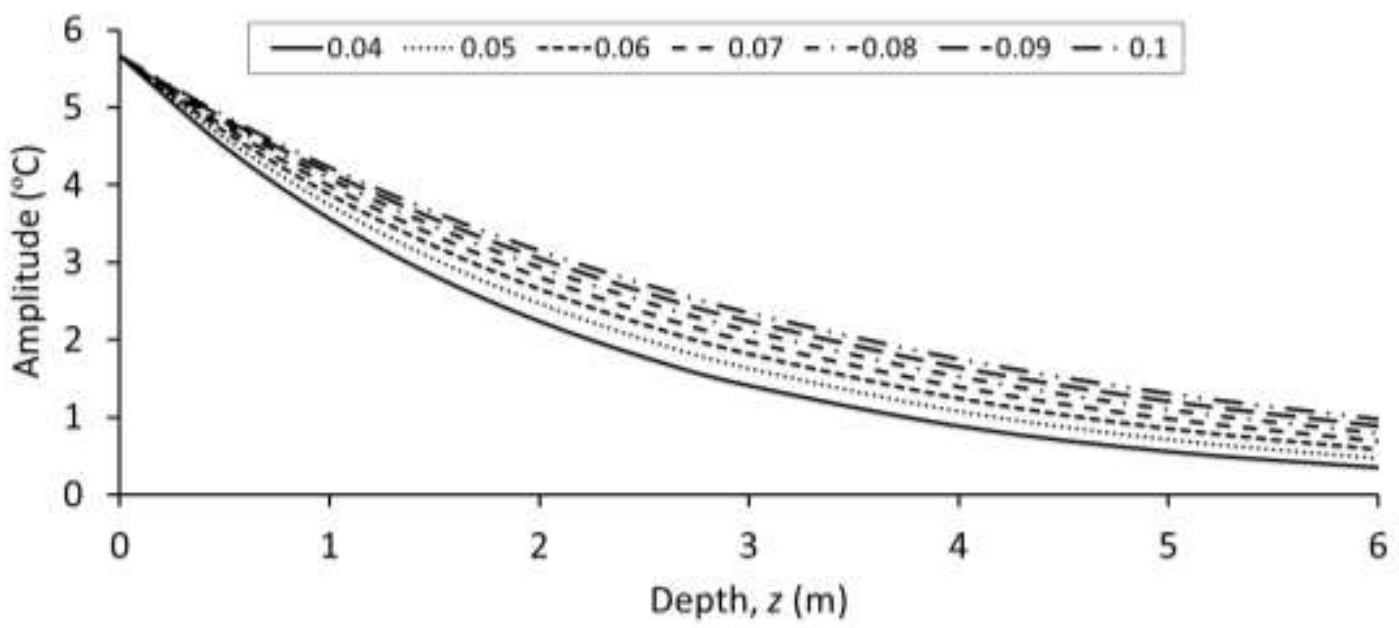

Figure 4. Amplitude of soil temperature as a function of depth.

Three correlation equations have been obtained from Figure 4 (in which $\alpha$ varies from 0.04 to $0.06 \mathrm{~m}^{2} /$ day), as stated below:

For $\alpha=0.04 \mathrm{~m}^{2} /$ day

$$
A_{s}=-0.0268 z^{3}+0.4188 z^{2}-2.4322 z+5.6329, \quad \mathrm{R}^{2}=0.9998
$$

For $\alpha=0.05 \mathrm{~m}^{2} /$ day

$$
A_{s}=-0.0217 z^{3}+0.3545 z^{2}-2.2117 z+5.6421, \quad \mathrm{R}^{2}=0.9999
$$

For $\alpha=0.06 \mathrm{~m}^{2} /$ day

$$
A_{s}=-0.018 z^{3}+0.3074 z^{2}-2.0411 z+5.6477, \quad \mathrm{R}^{2}=0.9999
$$

\section{Comparison and Validation}

The results in the present work have been compared with $[14,17,18]$. The comparison is conducted according to local weather conditions, but the value of thermal diffusivity is set the same, which is $0.05 \mathrm{~m}^{2} /$ day, and the depth ranges from 1 to $4 \mathrm{~m}$. Figure 5 shows comparisons of the results between the present work which is for the Malaysian condition and the three references. The result from [18] is slightly lower than the other results, but they still show some rationale for comparison purposes. The other two are very significant to compare with Malaysia's condition. At a shallow depth of $1 \mathrm{~m}$, there is a small difference at the beginning of the year between the present study and the results from [14] and [17]. The maximum temperature difference with [17] and [18] throughout the year is obtained at $5.6^{\circ} \mathrm{C}$ and $10.6{ }^{\circ} \mathrm{C}$, respectively. However, when the depth is increased from 2 to $4 \mathrm{~m}$, the temperature differences become smaller. This situation can be seen at a depth of $4 \mathrm{~m}$, whereby the maximum temperature differences are reduced to $1.7{ }^{\circ} \mathrm{C}$ and $7.3{ }^{\circ} \mathrm{C}$ for [17] and [14], respectively. Among these results, the temperature variation for the present study looks more consistent than the three references. Thus, underground temperature for the present study is more significant in implementing GHE for cooling purposes. Besides, the pattern of temperature variation in the present study is able to provide an adequately constant cooling capacity. 

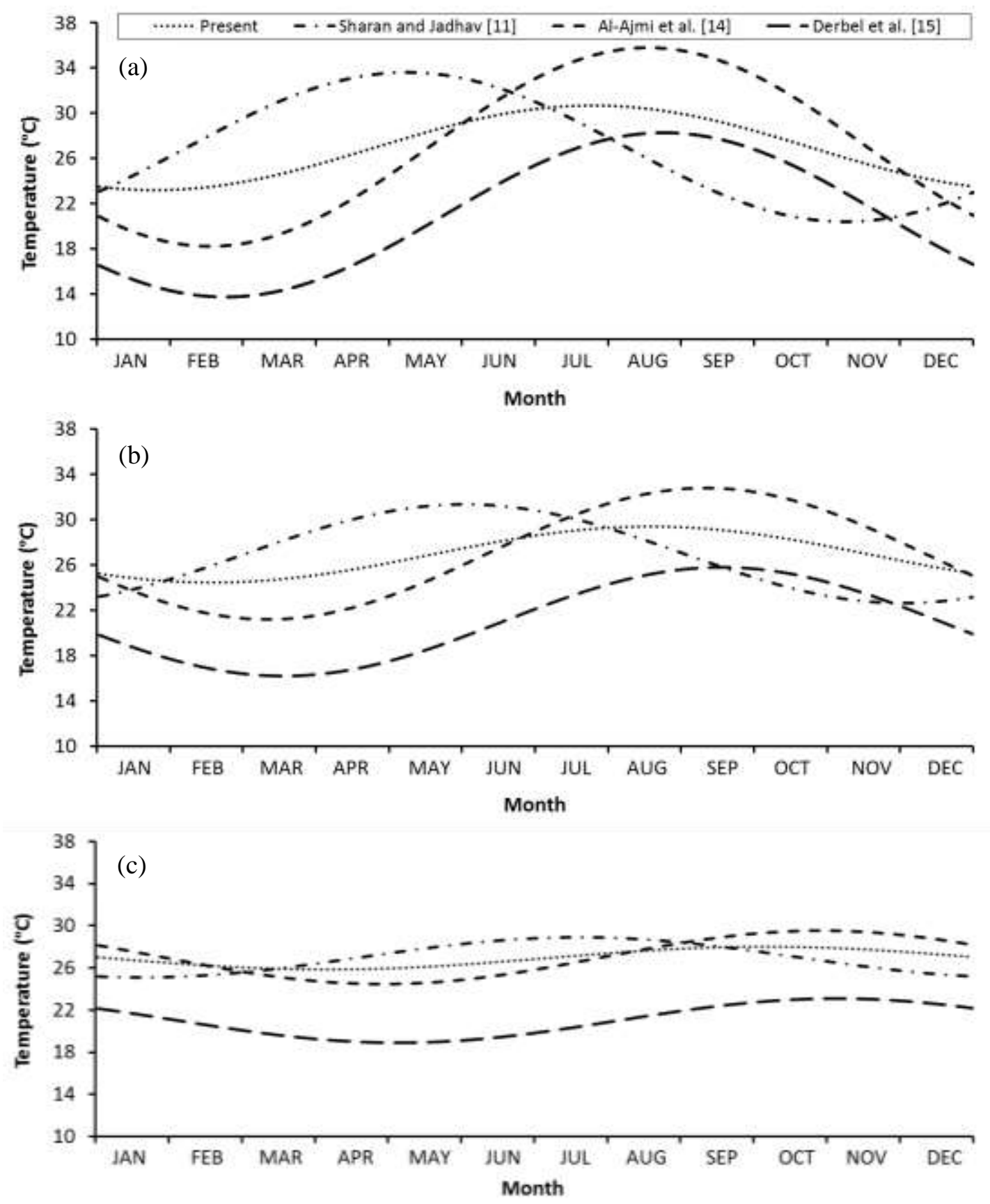

Figure 5. Comparison of temperature variations at depths of (a) $1.0 \mathrm{~m}$, (b) $2.0 \mathrm{~m}$ and (c) $4.0 \mathrm{~m}$.

\section{CONCLUSIONS}

The underground temperature for Malaysia's climate has been determined using empirical equations in which, at a depth below $2.0 \mathrm{~m}$, the GHE is able to produce significant passive cooling for any application. The temperature achieved ranges from 25 to $29^{\circ} \mathrm{C}$ with thermal diffusivities of $0.06 \mathrm{~m}^{2} /$ day and less. Deeper into the ground, the temperature variation will become consistent throughout the year and it will reach the same value as the annual mean air temperature. Although the underground temperature varies relatively with depth, the excavation cost to lay down the GHE should be considered in the implementation. In this study, the suitable depth at which to 
lay down the GHE is proposed as $2.5 \mathrm{~m}$ to $4.0 \mathrm{~m}$. Besides the depth, thermal diffusivity also plays a significant role in the annual underground temperature variation. It is recommended that the GHE be installed in a place having a thermal diffusivity of 0.06 $\mathrm{m}^{2} /$ day and less. Lesser thermal diffusivity would mean that the heat flow through the medium is slower and would result in a small temperature change.

\section{ACKNOWLEDGEMENTS}

The authors would like to thank the Faculty of Mechanical Engineering for providing the research facilities, and Universiti Malaysia Pahang for financial support under RDU130333.

\section{REFERENCES}

[1] IEC. Clean tech for cooling and heating of buildings. e-tech: Cooling and Heating. Switzerland: International Electrotechnical Commission; 2012. p. 4-7.

[2] Basrawi F, Ibrahim H, Taib MY, Lee GC. Optimum thickness of wall insulations and their thermal performance for buildings in malaysian climate. International Journal of Automotive and Mechanical Engineering. 2013;8:120717.

[3] Mahendran M, Lee GC, Shahrani A, Bakar RA, Kadirgama K. Diurnal pattern and estimation of global solar radiation in East Coast Malaysia. International Journal of Automotive and Mechanical Engineering. 2013;8:1162-75.

[4] Omer AM. Built environment: Relating the benefits of renewable energy technologies. International Journal of Automotive and Mechanical Engineering. 2012;5:561-75.

[5] Shekarchian M, Moghavvemi M, Motasemi F, Zarifi F, Mahlia TMI. Energy and fuel consumption forecast by retrofitting absorption cooling in Malaysia from 2012 to 2025. Renewable and Sustainable Energy Reviews. 2012;16:6128-41.

[6] Pfafferott J. Evaluation of earth-to-air heat exchangers with a standardised method to calculate energy efficiency. Energy and Buildings. 2003;35:971-83.

[7] Kasuda T, Archenbach PR. Earth Temperature and thermal diffusivity at selected station in the United States. ASHRAE Transaction. 1965;71:61-75.

[8] Argiriuou A. Ground cooling. In: Santamouris M, Asimakopoulos D, editors. Passive cooling of buildings. London: James \& James; 2001. p. 360-401.

[9] Florides G, Kalogirou S. Ground heat exchangers-A review of systems, models and applications. Renewable Energy. 2007;32:2461-78.

[10] Chow TT, Long H, Mok HY, Li KW. Estimation of soil temperature profile in Hong Kong from climatic variables. Energy and Buildings. 2011;43:3568-75.

[11] Pfafferott J, Walker-Hertkorn S, Sanner B. Ground cooling: recent progress. In: Santamouris M, editor. Advances in Passive Cooling. London: EarthScan; 2007. p. 190-227.

[12] Ascione F, Bellia L, Minichiello F. Earth-to-air heat exchangers for Italian climates. Renewable Energy. 2011;36:2177-88.

[13] Krishnan A, Rao GGSN. Soil temperature regime in the arid zone of India. Arch Met Geoph Biokl B. 1979;27:15-22.

[14] Sharan G, Jadhav R. Soil Temperature Regime at Ahmedabad. Journal of Agricultural Engineering. 2002;39. 
[15] Sharan G, Jadhav R. Performance of Single Pass Earth-Tube Heat Exchanger: An Experimental Study. Journal of Agricultural Engineering. 2003;40:1-8.

[16] Girja Sharan MT. Cropping in semi-arid Morthwest India greenhouse with ground coupling shading and natural ventilation for environmental control. International Journal for Service Learning in Engineering. 2010;5:148-69.

[17] Al-Ajmi F, Loveday DL, Hanby VI. The cooling potential of earth-air heat exchangers for domestic buildings in a desert climate. Building and Environment. 2006;41:235-44.

[18] Derbel HBJ, Kessentini I, Konoun O. Investigation of the underground temperature using neural network. 5th IEEE International Multi-Conference on System, Signals and Devices. Amman, Jordan 2008. p. 1-5.

[19] Alam MR ZM, Kaish ABMA. Energy efficient green building based on geo cooling system in sustainable construction of Malaysia. International Journal of Sustainable Construction Engineering \& Technology. 2012;3:96-105.

[20] Cui W, Liao Q, Chang G , Chen G, Peng Q, Jen TC. Measurement and prediction of undisturbed underground temperature distribution. ASME 2011 International Mechanical Engineering Congress and Exposition (IMECE2011). Denver, Colorado, USA: The American Society of Mechanical Engineers; 2011. p. 671-6.

[21] Sanusi ANZ, Shao L, Ibrahim N. Passive ground cooling system for low energy buildings in Malaysia (hot and humid climates). Renewable Energy. 2013;49:193-6.

[22] Penrod EB, Brown WK, Elliott JM. Variation of soil temperature at Lexington, Kentucky from 1952 - 1956. Soil Science. 1960;90:275-83.

[23] Kamil M, Rahman MM, Bakar RA. Performance evaluation of external mixture formation strategy in hydrogen fueled engine. Journal of Mechanical Engineering and Sciences. 2011;1:87-98.

[24] Mahendran M, Lee GC, Sharma KV, Shahrani A. Performance of evacuated tube solar collector using water-based titanium oxide nanofluid. Journal of Mechanical Engineering and Sciences. 2012;3:301-10.

[25] ASHRAE. ASHRAE HVAC System and Equipment. Atlanta, Ga: American Society of Heating, Refrigerating and Air-Conditioning Engineers, Inc; 2009.

[26] Derbel HBJ, Kanoun O. Investigation of the ground thermal potential in tunisia focused towards heating and cooling applications. Applied Thermal Engineering. 2010;30:1091-100.

[27] Perpar M, Rek Z, Bajric S, Zun I. Soil thermal conductivity prediction for district heating pre-insulated pipeline in operation. Energy. 2012;44:197-210.

[28] Lavoue F, Tourancheau B. Modeling and dimensioning heat exchangers principles: Influence of the soil's thermal properties. International Building Performance Simulation Association (IBPSA). France2010. p. 1-12.

[29] Ozgener O, Ozgener L, Tester JW. A practical approach to predict soil temperature variations for geothermal (ground) heat exchangers applications. International Journal of Heat and Mass Transfer. 2013;62:473-80. 